\title{
Ductus Venosus Flow and Myocardial Hypertrophy in Fetuses of Diabetic Mothers
}

\author{
Paulo Zielinsky, Silvana Marcantonio, Luiz Henrique Nicoloso, Stelamaris Luchese, \\ Domingos Hatem, Marlui Scheid, João Luiz Mânica, Eduardo loschpe Gus, Fabíola Satler, \\ Antônio L. Piccoli Jr. \\ Porto Alegre, RS - Brazil
}

\section{Objective}

To test the hypothesis that the pulsatility index of ductus venosus (PIDV) is greater in the fetuses of diabetic mothers (FDM) with myocardial hypertrophy (MH) than in the FDM with no $\mathrm{MH}$ and in the control fetuses of nondiabetic mothers (FNDM). Comparing the results with mitral and tricuspid diastolic peak flows.

\section{Methods}

The cross-sectional study included fetuses with gestational ages ranging from 20 weeks to term, divided into the following 3 groups: 56 FDM with $\mathrm{MH}$ (group I), 36 FDM with no $\mathrm{MH}$ (group II), and 53 FNDM (group III, control). The Doppler echocardiogram assessed the PIDV through the ratio (systolic velocity - presystolic velocity)/mean velocity. The mitral and tricuspid $E$ and $A$ waves were also assessed.

\section{Results}

The mean PIDV in groups I, II, and III were $1.13 \pm 0.64$, $0.84 \pm 0.38$, and $0.61 \pm 0.17$, respectively. Using ANOVA and the Tukey test, a statistically significant difference was found in the 3 groups $(P=0.015$ between groups $I$ and $I I ; P<0.001$ between groups I and III; and $P=0.017$ between groups II and III). The mean mitral $E$ wave was significantly greater in group I $(0.39 \pm 0.12 \mathrm{~m} / \mathrm{s})$ than in groups $\|(0.32 \pm 0.08 \mathrm{~m} / \mathrm{s})$ $(P=0.024)$ and $I I I(0.32 \pm 0.08 \mathrm{~m} / \mathrm{s})(P=0.023)$. The mean tricuspid $E$ wave was also greater in group I $(0.43 \pm 0.1 \mathrm{~m} / \mathrm{s})$ than in group III $(0.35 \pm 0.10 \mathrm{~m} / \mathrm{s})(P=0.031)$.

\section{Conclusion}

The PIDV is significantly greater in FDM with $M H$ than in FDM with no MH and in FNDM. Because the PIDV may represent modifications in ventricular compliance, this index may be a more sensitive parameter for assessing fetal diastolic function.

\section{Key words}

maternal diabetes; fetal myocardial hypertrophy;

ductus venosus; diastolic function

Fetal Cardiology Unit of the Instituto de Cardiologia of Rio Grande do Sul Fundação Universitária de Cardiologia - Postgraduation Program on Pediatrics of the Federal University of Rio Grande do Sul

Mailing address: Paulo Zielinsky - Instituto de Cardiologia do Rio

Grande do Sul - Unidade de Pesquisa - Av. Princesa Isabel, 395

Cep 90620001 - Porto Alegre, RS, Brazil

E-mail: zielinsky@cardiol.br / pesquisa@cardnet.tche.br

Received for publication: 6/25/03

Accepted for publication: 12/11/03

English version by Stela Maris Costalonga
In recent years, improvement in the management of diabetic pregnant women has been observed, with a reduction in maternalfetal morbidity and mortality ${ }^{1,2}$. Nevertheless, currently, up to $25 \%$ of the newborn babies of diabetic mothers have neonatal complications ${ }^{2}$.

The alterations resulting from maternal diabetes are due to fetal hyperinsulinemia associated with an increase in the number of insulin receptors in the heart, leading to hyperplasia and hypertrophy of myocardial cells, because of the increase in protein and fat synthesis ${ }^{3-6}$.

Fetal myocardial hypertrophy is the most frequently found abnormality in maternal diabetes mellitus, being observed in up to $35 \%$ of those babies ${ }^{7-10}$ (fig. 1 ).

The ventricular septum seems to be particularly rich in insulin receptors ${ }^{11}$, which could explain the more accentuated hypertrophy of that structure.

Alterations in left ventricular filling, depending or not on myocardial hypertrophy, have been reported between the 20th and 36 th gestational weeks ${ }^{12}$. The studies aimed to assess fetal diastolic function have used analysis of the $E / A$ ratio of mitral and tricuspid flows ${ }^{12,13}$.

Ductus venosus flow plays a fundamental role in fetal hemodynamics, and its analysis has been the object of study in several pathological situations ${ }^{14-19}$.

Because the flow of highly saturated blood to the foramen ovale depends directly on the velocity of ductus venosus flow ${ }^{20}$, it is rational to study that velocity in different phases of the cardiac cycle in fetuses of diabetic mothers with and without myocardial hypertrophy, and to compare it with that of control fetuses of nondiabetic mothers.

Because the pulsatility index of ductus venosus flow reflects its impedance, it may be a useful parameter for assessing the role of myocardial hypertrophy and of maternal diabetes in fetal diastolic ventricular function (fig. 2). Therefore, the conceptual hypothesis of this study is that fetuses with myocardial hypertrophy have greater impedance to the ductus venosus flow (with a greater pulsatility index) than do normal fetuses and fetuses without myocardial hypertrophy.

\section{Methods}

A cross-sectional observational study that included 56 fetuses of diabetic mothers and 53 healthy fetuses of nondiabetic mothers, 


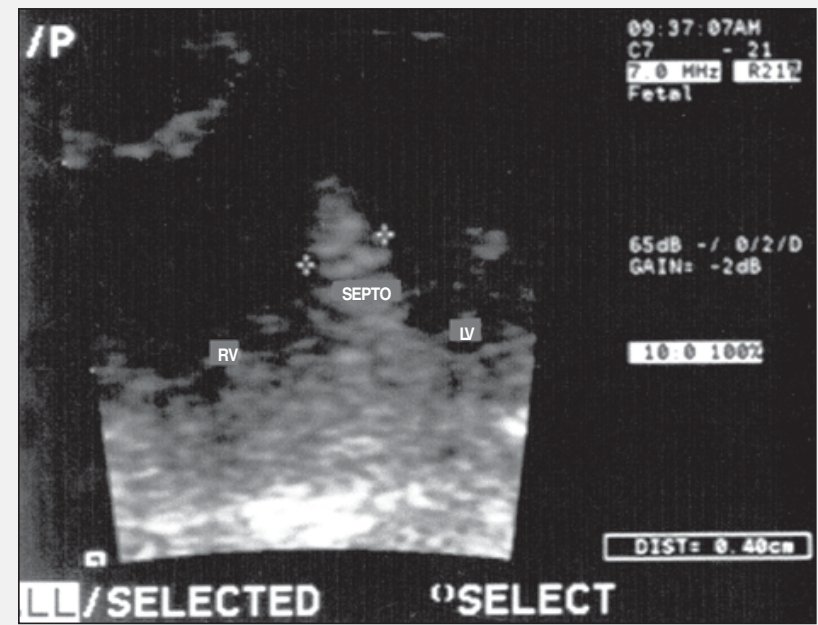

Fig. 1 - Echocardiogram of a fetus of a diabetic mother with myocardial hypertrophy. RV - right ventricle; LV - left ventricle.

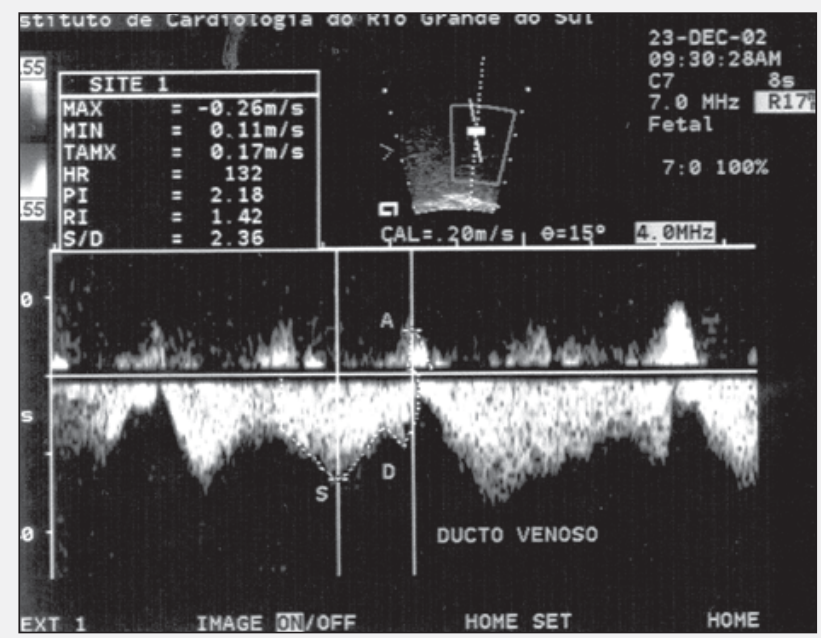

Fig. 2 - Upper panel: Doppler-echocardiogram of a healthy fetus showing a curve of ductus venosus flow and the obtainment of the pulse index. Lower panel: Doppler-echocardiogram of a fetus of a diabetic mother showing presystolic reverse ductus venosus flow.

whose gestational ages ranged from 20 weeks to term was carried out from October 2001 to December 2002.

The sample was divided into the following 3 groups: group I 20 fetuses of diabetic mothers with septal hypertrophy (FDM with $\mathrm{MH}$ ); group II - 36 fetuses of diabetic mothers without septal hypertrophy (FDM without $\mathrm{MH}$ ); group III - 53 control fetuses of nondiabetic mothers.

In the ultrasound assessment prior to cardiological evaluation, the fetal anatomy was analyzed to rule out malformations, as was fetal biometry to define gestational age ${ }^{21}$

Fetal echocardiographic examinations were performed in a sequential and segmentary manner ${ }^{22}$. Cardiac and vascular structures were studied in 4-chamber, longitudinal, transverse, and sagittal views.

At fetal Doppler echocardiography and color-flow mapping, special attention was given to the characteristics of the ductus venosus flow, as well as to the presence of myocardial hypertrophy and to mitral and tricuspid valve flows.

Myocardial hypertrophy was characterized by a ventricular septum thickness at the end of diastole greater than 2 standard deviations according to gestational age, using a previously des52 cribed technique and as a reference the nomogram proposed by
Allan ${ }^{23}$. The cursor was perpendicularly directed to the ventricular septum in a position distal to the leaflets of the atrioventricular valves, with 2-dimensional imaging in 4-chamber view.

The ductus venosus was identified by using a transversal view of the fetal abdomen at the level of the insertion of the umbilical cord. The pulsatility index for veins was used in the analysis of the ductus venosus, and its result was considered abnormal when values greater than the 95th percentile of the curve of normality for the corresponding gestational age were found based on the local nomogram ${ }^{24,25}$. Special attention was given to cases in which the ductus venosus was extremely altered with reverse flow during atrial contraction, because the placement of the sample volume in the intra-abdominal umbilical vein could simulate an abnormal ductus venosus. The venous pulsatility index (VPI), electronically calculated by the equipment after manual tracing of the velocities of the curve of the ductus venosus, was obtained with the following ratio: (maximum systolic velocity minus the presystolic velocity) divided by the mean velocity between the systolic, diastolic, and presystolic velocities (fig.2).

For comparison with the assessment of the ductus venosus flow, atrioventricular flows were analyzed by pulsed Doppler. The curves corresponding to the flow through the atrioventricular valves were obtained based on a 4-chamber view. The sample volume was placed immediately distal to the valvular leaflets, inside the ventricles. For obtaining the maximum velocities, only the fetuses in whom the ultrasound beam could be aligned with the blood flow in parallel or at an angle lower than $20^{\circ}$ were included in the study. The variables measured were the $A$ wave peak and $E$ wave peak in $\mathrm{m} / \mathrm{s}$ corresponding to the mitral and tricuspid flows. The $\mathrm{E} / \mathrm{A}$ ratio was calculated for each beat.

An echocardiographic device capable of 2-dimensional imaging, $\mathrm{M}$ mode, pulsed and continuous Doppler, and color mapping equipped with phased array and convex transducers from 2.0 to 7.0 $\mathrm{MHZ}$ was used in the study.

The studies were recorded for documentation and review. All pregnant women signed a written informed consent. The research was assessed and approved by the Committee on Ethics in Medical Research of the Instituto de Cardiologia of the Rio Grande do Sul/ Fundação Universitária de Cardiologia.

The quantitative data were reported as mean and standard deviation. The analysis of variance (ANOVA) was used for comparing the ductus venosus pulsatility index and the mitral and tricuspid flows in the 3 groups. The Tukey test was used for analysis of multiple comparisons. The ventricular septum was analyzed by using the Student $t$ test for comparison between groups I and II. The gestational age was controlled by analysis of covariance. The discriminating statistical significance level adopted was 0.05. Data were analyzed using the SPSS statistical program, version 11.0.

\section{Results}

Of the 118 fetuses studied, 9 were excluded (3 due to an inadequate acoustic window, 2 due to maternal hypertension, 1 due to omphalocele, and 2 due to fetal structural heart disease), which left 109 pregnancies between the 20th gestational week and term, of which 56 were diabetic and 53 nondiabetic. Of the diabetic women, $8(7.3 \%)$ had previous diabetes mellitus and 48 (44\%) had gestational diabetes.

The patients were divided into 3 groups: group I, comprising 
20 (18.3\%) fetuses of diabetic mothers with septal hypertrophy; group II, comprising 36 (33\%) fetuses of diabetic mothers without septal hypertrophy; and group III, comprising 53 (48.6\%) healthy fetuses of nondiabetic mothers. Maternal age, parity, and gestational age are shown in table I. No difference in glycemic levels was observed between groups I and II.

The means and medians of the glycemias and of the septal thicknesses are shown in table II. When applying the Student $t$ test, the ventricular septum was significantly thicker in group I than in group II $(P<0.001)$.

The pulsatility index of ductus venosus in the group of fetuses of diabetic mothers with septal hypertrophy (group I) ranged from 0.29 to 2.56 (mean $=1.13 \pm 0.64 ;$ median $=1.01)$. The pulsatility index of ductus venosus in group II ranged from 0.25 to 1.82 (mean $=0.83 \pm 0.38 ;$ median $=0.73$ ). The pulsatility index of ductus venosus in the control group ranged from 0.35 to 0.9 (mean $=0.61 \pm 0.17$; median $=0.6$ ) (fig. 3 and 4).

When applying the Tukey test and ANOVA, the mean and median pulsatility index were significantly higher in group I than in group II $(P=0.015)$ and group III $(P<0.001)$. Comparing the pulsatility index of ductus venosus in group II with that in group III, a statistically significant difference $(P=0.017)$ was observed. The significant difference between the groups was maintained even when controlling the gestational age with the covariance test.

Table III shows the values of the $E$ and $A$ waves of the mitral and tricuspid flows.

The mitral $E$ wave peak flow was significantly higher $(P=0.024)$ in group I than in groups II and III $(P=0.023)$ (fig. 5).

The tricuspid $\mathrm{E}$ wave peak flow was significantly higher in group I than in group III (P=0.031) (fig. 6); no difference was found between groups I and II (P=0.68).

\section{Discussion}

Infants of diabetic mothers have an established risk of developing myocardial hypertrophy even with adequate maternal metabolic control ${ }^{26,27}$. The manifestation of myocardial hypertrophy in the newborn ranges from the lack of symptoms to severe heart failure due to diastolic dysfunction ${ }^{28}$. The severity of the situation is related to the control of diabetes ${ }^{29}$. Microscopic alterations of the hypertrophic myocardium of the infants of diabetic mothers include, in addition to hyperplasia and hypertrophy, a disorganization of the normal pattern of the myofibrils, similar to that found in the cardiomyopathy of the adult ${ }^{30}$.

Diastole comprises the time period between closure of the semilunar valves and closure of the atrioventricular valves. It is divided into the following 4 phases: isovolumetric relaxation; rapid filling (related to ventricular relaxation); slow filling; and atrial contraction (related to compliance).

Doppler echocardiography is an adequate method for studying diastolic function in a noninvasive manner, using curves that relate time and velocity of ventricular filling ${ }^{31,32}$. Measurement of mitral and tricuspid flow velocities allows assessment of the volume of ventricular inflow during diastole, which, in turn, depends on the atrioventricular pressure gradient. Although this measurement does not allow a direct determination of diastolic function, it allows inferring information on ventricular relaxation and compliance ${ }^{33}$.

Studies confirming the value of Doppler echocardiography for assessing diastolic function used mainly Doppler recordings of the mitral valve ${ }^{34}$. During intrauterine life, systemic and pulmonary circulations act in parallel. Until the present time, assessing diastolic function of the fetal heart implyed in the study of mitral and tricuspid flows.

From the 10 th gestational week onwards, $E$ and $A$ waves may be identified ${ }^{34}$. The profile of diastolic filling through the atrioventricular valves shows a higher diastolic velocity in the atrial contraction phase (A wave) than in the beginning of diastole ( $E$ wave) ${ }^{35,36}$. The $E / A$ ratio is $<1$ during the entire fetal life.

According to Tsyvian et al ${ }^{12}$, in addition to myocardial hypertrophy in fetuses of diabetic mothers, an alteration in left ventricular filling occurs between the 20th and 36th gestational weeks. Left ventricular filling depends on myocardial diastole and is modified by several factors. An influence of the deterioration of the active force of afterload and compliance of the ventricular wall is observed. The ratio between early $(E)$ and late $(A)$ ventricular filling at the level of mitral and tricuspid valves (E/A ratio) at echocardiography

\begin{tabular}{|c|c|c|c|}
\hline \multicolumn{4}{|c|}{ Table I- Characteristics of the groups studied } \\
\hline & $\begin{array}{c}\text { Group I } \\
\text { FDM with MH } \\
(\mathrm{n}=20)\end{array}$ & $\begin{array}{c}\text { Group II } \\
\text { FDM without MH } \\
(n=36)\end{array}$ & $\begin{array}{l}\text { Group III } \\
\text { Healthy } \\
(n=53)\end{array}$ \\
\hline MA (years) & $32.26 \pm 7.34$ & $32.69 \pm 5.94$ & $31.19 \pm 6.24$ \\
\hline Number of gestations & $3 \pm 1.41$ & $2.89 \pm 1.53$ & $3 \pm 2.65$ \\
\hline Number of previous abortions & $0.6 \pm 0.68$ & $0.5 \pm 0.65$ & $0.67 \pm 1.15$ \\
\hline GA (weeks) & $32.95 \pm 2.97$ & $32 \pm 3.35$ & $26.09 \pm 3.72^{*}$ \\
\hline
\end{tabular}

FDM - fetuses of diabetic mothers; MH - myocardial hypertrophy; MA - maternal age; GA - gestational age. ${ }^{*} \mathrm{P}<0.001$ for comparisons between groups I and II and III

\begin{tabular}{|c|c|c|c|c|c|c|}
\hline & $\begin{array}{c}\text { Group I } \\
\text { FDM with MH } \\
(n=20)\end{array}$ & (median) & $\begin{array}{c}\text { Group II } \\
\text { FDM without MH } \\
(n=36)\end{array}$ & (median) & $\begin{array}{l}\text { Group III } \\
\text { Controls }\end{array}$ & (median) \\
\hline VS & $0.49 \pm 0.08$ & $(0.48)$ & $0.32 \pm 0.05^{*}$ & $(0.32)$ & $0.32 \pm 0.03$ & (0.32) \\
\hline
\end{tabular}


is used to establish the contribution of atrial contraction to total transmitral flow. As already mentioned, these indices have been the major indirect measurements of diastolic function. Rizzo et al ${ }^{13}$ reported a reduction in diastolic function in fetuses of diabetic mothers expressed by this ratio. A reduced ventricular compliance in fetuses of diabetic mothers could be secondary to wall thickening or to other factors, such as metabolic alterations in the uterine environment associated with qualitative changes in collagen (an increase in the fluorescent collagen in the myocardium) ${ }^{12}$. The higher $\mathrm{E}$ wave velocity in mitral and tricuspid valves in the group of fetuses of diabetic mothers with myocardial hypertrophy found in this study could reflect an altered pattern of relaxation. Tsyvian et al ${ }^{12}$, in a study including fetuses of insulin-dependent diabetic mothers, showed a reduction in diastolic function, using the $E / A$ ratio. Macklon et al ${ }^{37}$, studying the cardiac function of fetuses of diabetic mothers between the 18th and 20th gestational weeks, found no difference comparing to the control group, contrary to results of previous studies reporting a reduction in $E / A$ ratio in the atrioventricular valves and high values of peak velocity in the outflow tracts between the 20th and 36th gestational weeks. These findings may merely reflect the early phase in which these fetuses were examined, indicating that functional changes become

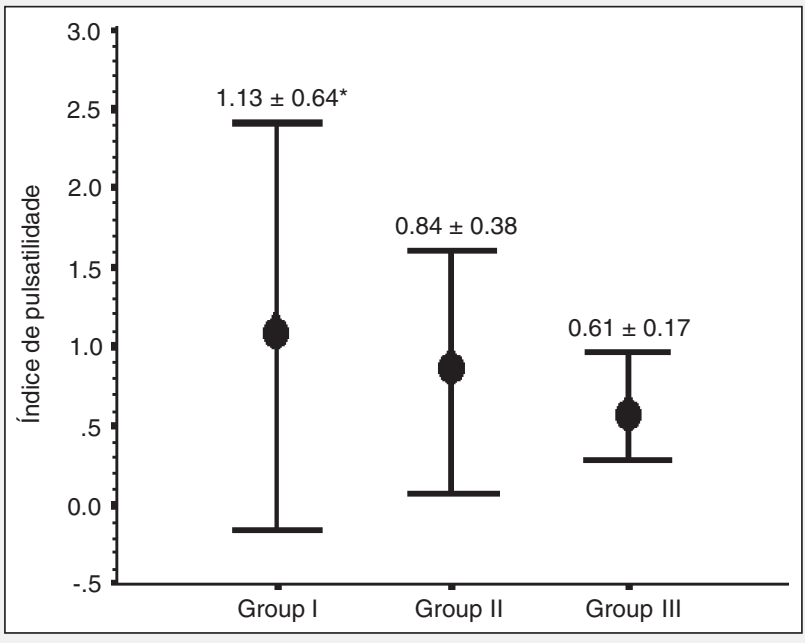

Fig. 3 - Comparison between the means of the pulse index of FDM with $\mathrm{MH}$ in group I, FDM without $\mathrm{MH}$ in group II, and healthy fetuses in group III. ${ }^{*} \mathrm{P}=0.015$ between groups I and $\|, \mathrm{P}<0.001$ between groups I and II and III, and $\mathrm{P}=0.017$ between groups $\mathrm{II}$ and III.

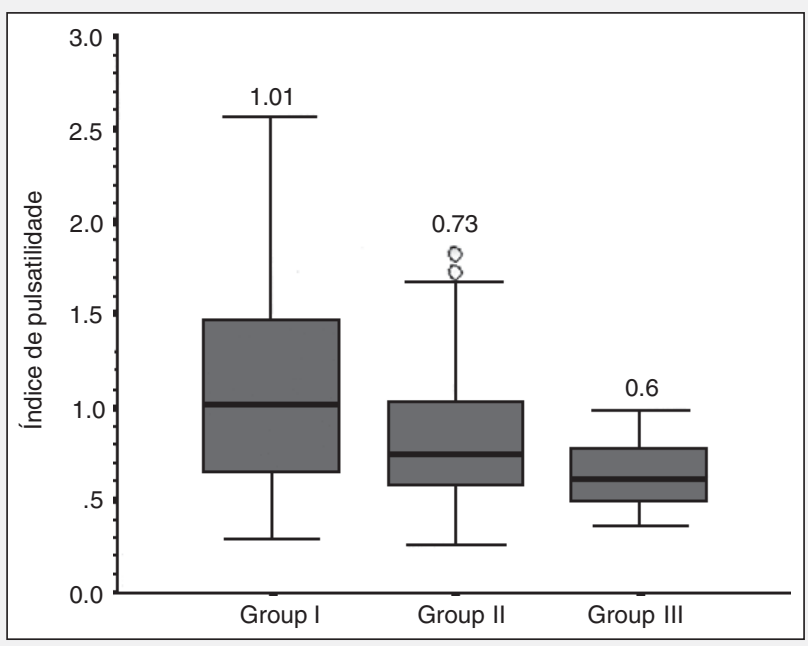

Fig. 4 - Comparison between the medians of the pulse indices in groups I, II, and III.

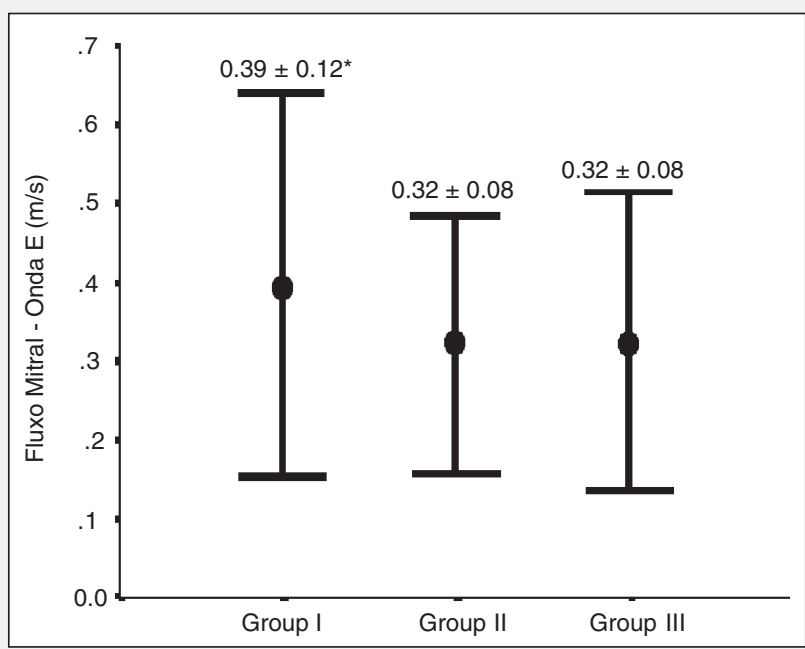

Fig. 5 - Comparison between the means of the mitral $E$ wave in group I, group II, and group III. ${ }^{*} \mathrm{P}=0.024$ between groups I and II, and $\mathrm{P}=0.023$ between groups I and III.

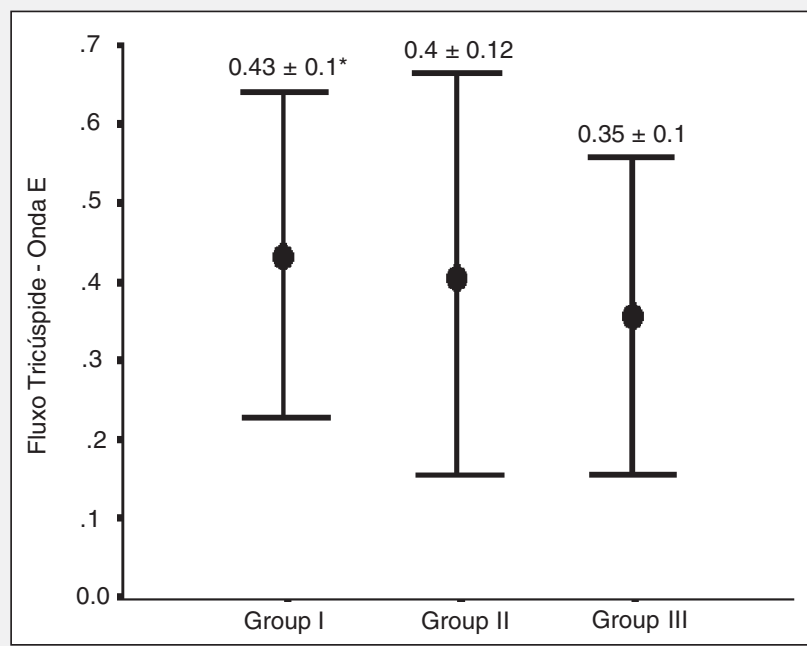

Fig. 6 - Comparison between the means of the tricuspid $E$ wave in group I, group II, and group III. * $P=0.031$ in comparison between groups I and III.

\begin{tabular}{|lcc|}
\hline \multicolumn{2}{|c|}{ Table III - Doppler-echocardiographic parameters of the mitral and tricuspid E wave in the fetuses of diabetic mothers (FDM) with and without myocardial } \\
hypertrophy (MH) and healthy fetuses
\end{tabular}


evident late in gestations influenced by diabetes, or suggest that the analysis of the atrioventricular flows may not be sensitive enough to assess diastolic function.

Rizzo et al ${ }^{38}$, studying cardiac and venous flows by using an association of transvaginal and Doppler echocardiograms, reported evidence of dramatic changes in the flow pattern between the 11 th and 20th gestational weeks. These changes are more significant than those occurring in late pregnancy, suggesting a period of rapid development of the fetal heart. Therefore, metabolic abnormalities, such as those observed in maternal diabetes, may affect and hinder the early development of the fetal heart. When studying the cardiac venous flow of fetuses of controlled and noncontrolled diabetic mothers and comparing it with that in a control group, fetuses of diabetic mothers had a smaller increase in the $E / A$ ratio, a smaller decrease in the reverse flow in the inferior vena cava, and pulsations in the umbilical vein up to the 16 th gestational week. These alterations may be the reflex of changes in preload, afterload, or ventricular compliance.

This study assesses the behavior of the ductus venosus flow in fetuses of diabetic mothers with and without myocardial hypertrophy, and compares it with that in healthy fetuses of nondiabetic mothers. Fetuses of diabetic mothers with septal hypertrophy showed a significantly higher pulsatility index of the ductus venosus than fetuses of diabetic mothers without septal hypertrophy and control fetuses, confirming the conceptual hypothesis. This behavior may be attributed to changes in diastolic ventricular function in fetuses with myocardial hypertrophy, because the pulsatility index of the ductus venosus flow represents its impedance during the cardiac cycle, which is influenced by ventricular filling capacity. It is worth stressing that the difference found between groups II and III suggests that other factors, in addition to myocardial hypertrophy, interfere with fetal diastolic function in maternal diabetes.

Although the pulse index of the ductus venosus did not have a normal distribution, the values of the mean and median ductus venosus flows did not disagree. Therefore, we chose to report the means and to perform the parametric tests for comparison with other studies.

Assessment of the flow through the mitral and tricuspid valves showed that the $E$ wave in both valves was significantly greater in fetuses with myocardial hypertrophy than in control fetuses, suggesting that the diastolic relaxation of both ventricles was altered in the presence of wall hypertrophy. No difference was observed in mitral and tricuspid A waves (reflecting an alteration in ventricular compliance). However, the results observed in the analysis of the ductus venosus flow suggest that ventricular compliance is impaired as a consequence of myocardial hypertrophy and maternal diabetes, indicating that the assessment of the ductus venosus may be more sensitive than the analysis of atrioventricular flows for detecting a decrease in ventricular compliance.

Our results differ from those of Rizzo et al ${ }^{38}$ probably because our study comprised pregnant women at more advanced gestational ages, emphasizing the idea that earlier gestational changes are more evident than those appearing later, which was suggested by the authors themselves. In addition, in the study by Rizzo et al ${ }^{38}$, fetuses of diabetic mothers were not divided into 2 groups (with and without hypertrophy), as in our study. Knowing that myocardial hypertrophy is related to abnormalities in ventricular relaxation, changes in the early filling phase were expected in fetuses of diabetic mothers with myocardial hypertrophy as compared with fetuses of diabetic mothers without myocardial hypertrophy and fetuses of nondiabetic mothers, which was actually shown.

In conclusion, fetuses of diabetic mothers with myocardial hypertrophy have impairment in ductus venosus flow with an increase in the pulsatility index of that flow as compared with fetuses of diabetic mothers with normal myocardial thickness and normal fetuses of nondiabetic mothers. This behavior may be related to changes in fetal diastolic function, which affect ventricular relaxation and compliance, as a consequence of myocardial hypertrophy and maternal diabetes mellitus.

\section{References}

1. Montenegro JR, Paccala G, Faria C et al. Evolução materno-fetal de gestantes diabéticas seguidas no HC-FMRP - USP no período de 1992-1999. Endocrinol e Metabolog 2001; 45: 467-74.

2. Hod M, Dye TD. Perinatal complications following gestational diabetes mellitus How sweet is ill ? Acta Obstet Gynecol Scand 1996; 75: 809-15.

3. Zielinsky P, Costa M, Oliveira L, Telles M, Hagemann L. Estudo da história natural da hipertrofia miocárdica e sua associação com hiperinsulinismo em filhos de mães diabéticas. Arq Bras Cardiol 1997; 69: 389-94.

4. Zielinsky P, Hagemann L. Estudo pré-natal da miocardiopatia hipertrófica e sua associação com niveis de insulina em fetos de mães diabéticas. Arq Bras Cardiol 1996; 66: 193-8.

5. Sheehan P, Rowland T, Shah B, McGravey V, Reiter E. Maternal diabetic control and hypertrophic cardiomyopathy in infants of diabetic mothers. Clin Ped 1986; 25: $266-71$.

6. Menezes HS, Barra M, Belló A, Martins CB, Zielinsky P. Fetal myocardial hypertrophy in a experimental model gestational diabetes. Cardiol Young 2001; 11:609-13.

7. Behle I, Zielinsky P, Zimmer L, Pontremoli M, Rish J. Níveis de hemoglobina glicosilada e anomalias cardíacas em fetos de mães com diabetes melito. Revista Brasileira de Ginecologia e Obstetrícia 1998; 20: 237-43.

8. Cousins L. Congenital anomalies among infants of diabetic mothers. Am J Obstet Gynecol 1983; 147: 333-8.

9. Albert TJ, Landon MB, Wheller JJ et al. Prenatal detection of fetal anomalies in pregnancies complicated by insulin - dependent diabetes mellitus. Am J Obstet Gy necol 1996; 174: 1424-8.
10. Sardesai M, Gray A, McGrath M. Fatal hypertrophic cardiomyopathy in the fetus of a woman with diabetes. Obstet Gynecol 2001; 98: 925-7.

11. Thorson AV, Hintz RL. Insulin receptors in the newborn. Increase in receptor affinity and number. N Engl J Med 1977; 297: 908-12.

12. Tsyvian $P$, Malkin $K$, Artemiva $O$, Wladimiroff JW. Assessment of left ventricular filling in normally grown fetuses, growth-restricted fetuses and fetuses of diabetic mothers. Ultrasound Obstet Gynecol 1998; 12: 33-8.

13. Rizzo G, Arduini, romanini C, Mancuso S. Doppler echocardiographic assessments of atrioventricular velocity waveforms in normal and small for gestational age fetuses. Brit J Obstet Gynecol 1988; 95: 65-9.

14. Campbell S, Mavrides E, Prefumo F, Presti F, Carvalho TS. Prenatal diagnosos of mosaictrisomy 8 in a fetus with normal nuchal translucency thickness and reversed end- diastolic ductus venosus flow. Ultrasound Obstet Gynecol 2001; 17: 341-3.

15. Fugelseth $D$, Kiserud $T$, Liestol $K$, Langslet $A$, Lindemann R. Ductus venosus blood velocity in persistent pulmonary hypertension of the newborn. Arch Dis Fetal Neonatal Ed 1999; 81: 35-9.

16. Borrel A, Antolin E, Costa D, Farre MT, Martinez JM, Fortunny A. Abnormal ductus venosus blood flow in trisomy 21 fetuses during early pregancy. Am J Obstet Gynecol 1998; 179: 1612-17.

17. Tchirikov M, Rybakowski C, Huneke B, Schroeder H. Blood flow through the ductus venosus in singleton and multifetal pregnancies and in fetuses with intrauterine growth retardation. Am J Obstet Gynecol 1998; 178: 943-9.

18. Hecher $\mathrm{K}$, Bilardo $\mathrm{CM}$ et al. Monitoring of fetuses with intrauterine growth restriction: a longitudinal study. Ultrasound Obstet Gynecol 2001; 18: 564-70. 
19. Kiserud T, Rasmussen S, Skulstad S. Blood flow and the degree of shunting through the ductus venosus in the human fetus. Am J Obstet Gynecol 2000; 182: 147-53.

20. Kiserud T. Hemodynamics of the ductus venosus. Eur J Obstet Gynecol 1999; 84: 139-47.

21. Sabbagha RE, Hughey M. Standardization of sonar cephalometry and gestational age. Obstet Gynecol 1978; 52: 402-6.

22. Zielinsky P, Haertel JC, Lucchese F. Abordagem sequencial das cardiopatias congênitas: um enfoque ecocardiográfico bidimensional. Arq Bras Cardiol 1985; 45: 129-44.

23. Allan LD. The normal fetal heart. In: Allan L, Hornberger L, Sharland G. Textbook of Fetal Cardiology. London: Greenwich Medical Media Ltda, 2000: 55-102.

24. Bahlmann F, Wellek S, Reinhardt I, Merz E, Steiner E, Welter C. Reference values of ductus flow velocities and calculated waveform indices. Prenat Diagn 2000; 20:623-34.

25. Hecher K, Campbell S, Snijders R, Nicolaides K. Reference ranges for fetal venous and blood flow parameters. Ultrasound Obstetr Gynecol 2003; 4: 381-90.

26. Rizzo G, Arduini D, Romanini C. Accelerated cardiac growth and abnormal cardiac flow in fetuses of type I diabetic mothers. Obstet Gynecol 1992; 80: 369-76.

27. Oberhoffer R, Högel J, Stoz F, Kohne E. Cardiac and extracardiac complications in infants of diabetic mothers and their relations to parameters of carbohydrate metabolism. Eur JPed 1997; 156: 262-5.

28. Mace S, Hirschfeld SS, Riggs T, Fanaroff AA, Merkatz I. Echocardiographic abnormalities in infants of diabetic mother. JPed 1979; 95: 1013-19.

29. Ray JG, O'brien TE, Chan WS. Preconception care and the risk of congenital ano- malies in the offspring of women with diabetes mellitus: a meta-analysis. Q J Med 2001; 94: 435-44.

30. Gutgesell P, Speer M, Rosemberg HS. Characterization of the cardiomyopathy in infants of diabetic mothers. Circulation 1980; 61: 441-50.

31. Hahn H, Hoit B. Doppler echocardiographic assessment of diastolic ventricular function: transmitral and pulmonary venous flow indices. Pediatr Cardiol 1999; 10: 95-103.

32. Little W, Warner J, Rankin K, Kitzman D. Evaluation of left ventricular diastolic function from the pattern of left ventricular filling. Clin Card 1998; 21: 5-9.

33. Thomas JD, Weyman AE. Echocardiographic Doppler evaluation of left ventricular diastolic function - physics and physiology. Circulation 1991; 84: 977-90.

34. Demaria AN, Wisenbaugh T. Identification and treatment of diastolic dysfunction: role of transmitral Doppler recordings. JAm Coll Cardiol 1987; 9: 1106-7.

35. van Splunder IP, Wladimiroff W. Cardiac functional changes in the human fetus in the late first and early second trimesters. Ultrasound Obstet Gynecol 1996; 7: 411-15.

36. Kenny JF, Plappert T, Doubilet $P$ et al. Changes in intracardiac blood flow velocities and right and left ventricular stroke volumes with gestational age in the normal human fetus: a prospective Doppler echocardiography study. Circulation 1986; 74: 1208-16.

37. Macklon N, Hop WC, Wladimiroff JW. Fetal cardiac function and septal thickness in diabetic pregnancy: a controlled observational and reproducibility study. Brit J Obstet Gynecol 1998; 105: 661-66.

38. Rizzo G, Arduini D, Capponi A, Romanini C. Cardiac and venous blood flow in fetuses of insulin-dependent diabetic mothers: evidence of abnormal haemodynamics in early gestation. Am J Obstet Gynecol 1995; 173: 1775-81. 